\title{
Influence of heat stress on the reproduction rates of sows of the Poltava meat breed, depending on the genotype
}

\author{
Natal ya Garskaya ${ }^{1}$, Lidiya Peretyatko $^{2}$, Sergey Pozyabin ${ }^{3}$, Sergey Tresnitskiy ${ }^{4}$, and \\ Anatoliy Tresnitskiy ${ }^{4}$ \\ ${ }^{1}$ Lugansk State Pedagogical University, Oboronnaya Str., 2, 91002 Lugansk \\ ${ }^{2}$ Institute of Pig Breeding and agroindustrial production of NAAS of Ukraine, Shvedskaya Mogila \\ Str., 1, 36013 Poltava, Ukraine \\ ${ }^{3}$ Moscow State Academy of Veterinary Medicine and Biotechnology - MVA by K.I. Scryabin, \\ Akademika Scriabin str., 23, 109472 Moscow, Russia \\ ${ }^{4}$ Don State Technical University, sq. Gagarin, 1, 3440003 Rostov-on-Don, Russia
}

\begin{abstract}
The article deals with the issues of the influence of heat stress that occurs in the summer on the indicators characterizing the reproductive qualities. Purebred sows of tested Poltava meat breed of different genotypes were investigated: Group I - individuals-offspring obtained by the method of introductory crossing using the blood of early maturing meat breed (blood content 12.5\%), Group II - individuals obtained by the method of introductory crossing using the blood of the Finnish Landrace (blood content of $12.5 \%$ ). It was found that in sows of the Poltava meat breed with the blood of early maturing meat breed, the number of live piglets at birth significantly exceeds the indices of sows with the blood of the Finnish Landrace by $8.27 \%$ at $p \leq 0.05$. According to the analysis of $\mathrm{Cv}$, these natural and technological conditions had the greatest influence on the duration of the service period in sows of Group I. Wherein, the least influence of these natural and technological conditions was found for the indicator of the duration of pregnancy. Animals with the blood of an early maturing meat breed were more adaptable to these natural and technological conditions.
\end{abstract}

\section{Introduction}

According to forecasts, by $2030-2052$ the global climate change will lead to $1.5^{\circ} \mathrm{C}$ rise in temperature. If it continues at the current pace, the number of hot days is projected to increase in most land regions [1]. It is also predicted that the frequency, intensity and duration of heat waves will increase in the future [2]. Currently, little is known about how this might affect the well-being of living organisms.

Extreme temperature events caused by climate change can increase the risk of exceeding the body's thermoregulatory capacity [3]. All animals have a thermal comfort zone to maintain physiological functions. However, under conditions when the temperature rise goes beyond the upper critical temperature range, animals begin to experience heat stress [4]. 
Heat stress caused by high ambient temperatures adversely affects the health and productivity of animals [5-7]. Pigs are especially vulnerable to heat stress [8]. In pigs, heat stress markedly increases respiration rate and body temperature, significantly reduces feed intake, endangers brain and intestinal health, and increases mortality and morbidity $[5,9$, $10]$.

Depending on the severity, heat stress can have moderate or severe effects on many aspects of reproductive function in both males and females [11]. Short-term overheating of the testes in males can lead to temporary infertility [12]. Among the most noticeable effects of heat stress in females are low fertility [11], impaired fetal development, and reduced birth weight in humans, rats, cattle, and pigs [13].

The nature of the response of animals to meteorological parameters can differ depending on climatic conditions, production systems, or both [14]. In addition, it was found that the adaptive ability of animals to heat stress has a genetic component [15]. Highly productive modern pig breeds are usually bred in countries with continental or temperate continental climates, which means, that they are sensitive to heat. To minimize production and profitability losses in pig production associated with exposure to heat stress, it is necessary to search for preventive strategies that can mitigate the adverse effects of this natural factor.

The purpose of our paper is to study the effect of heat stress on the reproduction rates of sows of the Poltava meat breed, depending on the genotype.

\section{Materials and Methods}

The studies were carried out in the conditions of LLC «Plemzavod «Belovodskiy»»» (Lugansk region, Ukraine) on a purebred livestock of tested sows of the Poltava meat breed. All animals belonged to the elite and first classes.

Poltava meat breed of pigs is a breed of meat productivity direction. Through introductory crossing in the breed, new genotypes were created with pigs of the Finnish Landrace breed (to improve meat qualities) and early maturing meat one (to improve adaptive qualities). For study, we formed two groups on the principle of analog pairs: Group I - sows-offspring of introductory crossing, with a share of early maturing meat breed blood of $12.5 \%(n=7)$, Group II - sows-offspring of introductory crossing, with a share Finnish Landrace blood of $12.5 \%(n=10)$. The data on the genotype and reproductive capacity of the sows were taken from the materials of the breeding and zootechnical records.

All sows received the same diet under the same conditions. The feeding conditions and maintenance of all groups corresponded to the feeding standards of the Institute of Pig Breeding and Agroindustrial Production of the National Academy of Sciences of Ukraine, taking into account age, live weight and physiological state. The type of feeding is concentrate, using feed of our own production. The keeping of animals is free-range.

According to climatic data in the Lugansk region, the warm period of the year is considered to be from May 1 to October 1. Based on long-term observations of the Lugansk meteorological station, it has been established that the summer months are the warmest in the region. The average temperature of the warmest month of the year, July, averages to + $21{ }^{\circ} \mathrm{C}$. The number of days with a maximum air temperature above $25^{\circ} \mathrm{C}$ is about 109 days a year. The number of days with a maximum air temperature above $30{ }^{\circ} \mathrm{C}$ is about 56 days a year (the effect of this temperature can be considered mild heat stress for animals [16]). For the study, sows tested were selected whose pregnancy took place in the warmest period of the year (from May to September).

Statistical data processing was performed using the STATISTICA (6.0) software package, with the assumption of a probability of $\mathrm{p} \leq 0.05$. 


\section{Results}

The data obtained for the indicators of reproductive qualities of the tested sows of the Poltava meat breed of various genotypes are shown in Table 1.

Table 1. Indicators of reproductive qualities of tested sows of Poltava meat breed of various genotypes, $(\mathrm{M} \pm \mathrm{m})$

\begin{tabular}{|c|c|c|}
\hline \multirow{3}{*}{ Indicator } & \multicolumn{2}{|c|}{ Genotype } \\
\hline & $\begin{array}{c}12.5 \% \text { early } \\
\text { maturing meat breed }\end{array}$ & $\begin{array}{l}12.5 \% \text { Finnish } \\
\text { Landrace breed }\end{array}$ \\
\hline & Group I(n=7) & Group II $(n=10)$ \\
\hline Duration of pregnancy, days & $119.57 \pm 3.08$ & $114.7 \pm 0.56$ \\
\hline $\mathrm{Cv}, \%$ & 6.83 & 1.54 \\
\hline Total piglets were born, heads & $11.0 \pm 0.53$ & $12.5 \pm 0.76$ \\
\hline $\mathrm{Cv}, \%$ & 12.82 & 19.36 \\
\hline Live piglets born, heads & $11.0 \pm 0.53$ & $11.4 \pm 0.72$ \\
\hline $\mathrm{Cv}, \%$ & 12.82 & 19.91 \\
\hline Live piglets were born, $\%$ & $100.0 \pm 0 *$ & $91.73 \pm 3.04^{*}$ \\
\hline $\mathrm{Cv}, \%$ & - & 10.49 \\
\hline Big fetus, $\mathrm{kg}$ & $1.0 \pm 0$ & $1.04 \pm 0.04$ \\
\hline $\mathrm{Cv}, \%$ & - & 12.11 \\
\hline Nest weight at birth, kg & $11.0 \pm 0.53$ & $11.44 \pm 0.72$ \\
\hline $\mathrm{Cv}, \%$ & 12.82 & 19.84 \\
\hline Number of piglets weaned at 45 days, heads & $10.14 \pm 0.26$ & $10.38 \pm 0.31$ \\
\hline $\mathrm{Cv}, \%$ & 6.8 & 9.44 \\
\hline Weight of one head weaned at 45 days, $\mathrm{kg}$ & $9.61 \pm 0.46$ & $10.88 \pm 0.72$ \\
\hline $\mathrm{Cv}, \%$ & 12.69 & 20.86 \\
\hline Nest weight at weaning at 45 days, $\mathrm{kg}$ & $82.43 \pm 12.72$ & $108.85 \pm 8.08$ \\
\hline $\mathrm{Cv}, \%$ & 40.83 & 7.42 \\
\hline Safety level, \% & $92.02 \pm 4.32$ & $89.74 \pm 2.38$ \\
\hline $\mathrm{Cv}, \%$ & 12.42 & 8.38 \\
\hline Service period, days & $75.75 \pm 21.36$ & $52.56 \pm 4.68$ \\
\hline $\mathrm{Cv}, \%$ & 56.42 & 26.71 \\
\hline
\end{tabular}

* - the probability of a difference between the groups $\mathrm{p} \leq 0.05$

The results of the conducted studies show that the tested sows of the Poltava meat breed with a blood rate of $12.5 \%$ for the early maturing meat breed (Group I) had the longest gestation period, surpassing animals with the blood of the Finnish Landrace by 4.87 days or $4.07 \%$. However, the established difference was not significant.

Animals of Group II, with the blood of the Finnish Landrace, exceeded the indicators of Group I in the number of born piglets by 1.5 heads or $8 \%$, in the number of live piglets born - by 0.4 heads or $3.51 \%$, respectively. However, the established difference was only physical, i.e. unreliable. Wherein, when calculating the relative number of live piglets born, we established a significant superiority of sows with the blood of early maturing meat breed by $8.27 \%$ at $\mathrm{p} \leq 0.05$.

Piglets of sows with Finnish Landrace blood were larger at birth and at weaning (by $0.04 \mathrm{~kg}$ or $3.85 \%$ and $1.27 \mathrm{~kg}$ or $11.67 \%$, respectively). Piglet weight affected nest performance at birth and weaning, respectively. In the nests of animals of Group II, the mass was greater: at birth — by $0.4 \mathrm{~kg}$ or $3.63 \%$, at weaning — by $26.42 \mathrm{~kg}$ or $24.27 \%$. However, there were no significant intergroup differences in the indicators.

In the nests of sows with the blood of early maturing meat breed, the survival rate of piglets during the period of stay with the mother was slightly higher (by $2.28 \%$ ). However, after weaning, the sows of this group showed a slight increase in the service period (by 23.19 days or $30.61 \%$ ), but the established difference was only physical. 
Based on the values of the obtained data of the coefficient of variation $(\mathrm{Cv})$, it follows that these natural and technological conditions had the greatest effect on duration of the service period in sows of Group I. Wherein, the least influence of these natural and technological conditions was found for the indicator of the duration of pregnancy. The value of this indicator in sows with Finnish Landrace blood $(\mathrm{Cv}=1.54 \%)$, which may indicate the "pressing" effect of selection (artificial selection) is noteworthy.

Most of the studied indicators are homogeneous $(\mathrm{Cv} \leq 32 \%)$ and average variability of indicators, i.e. depend both on the genotype of animals and on environmental factors. The indicator of the mass of the nest at weaning at 45 days and duration of the service period in animals with the blood of an early maturing meat breed is to a greater extent than other indicators due to environmental factors.

\section{Discussion}

The study is one of the attempts to find out the production potential of sows of the Poltava meat breed in terms of characteristics of their adaptability to the hot summer conditions of the breeding zone, by assessing the reproductive qualities of animals.

We found that the ability of sows of the Poltava meat breed to endure hot weather has a genetic dependence and significantly affects the number of live piglets at birth. Seasonal loss of piglets can become a serious problem in pig production in this region when using non-adapted genotypes or lead to economic costs to ensure microclimate indicators.

Sows with early maturing meat breed blood are more adapted to heat stress conditions. The established tendency to an increase in gestation in these animals is also probably associated with adaptive properties. It is known that among the factors that form the environmental conditions of prenatal and postnatal growth in the milk period, the maternal resource, directed to the growth and development of the fetus, probably plays the main role. Probably, sows of this group during pregnancy "spend" more body reserves, which further affects the postnatal growth of piglets, their weight and weight of the nest. In order to level the differences in the growth of piglets of sows of the Poltava meat breed with the blood of the early maturing meat breed, it is necessary to correct the conditions of feeding and keeping the animals.

The infusion of the blood of the Finnish Landrace, to improve the meat qualities of animals, created conditions for formation of better meat productivity in the offspring, but increased the "tension" of the body's defense systems in sows, which was manifested in a decrease in the number of viable piglets. Our findings are consistent with the opinion of Le $\mathrm{HH}$ et al. (2020) [17] that intensive genetic selection to increase productivity also makes animals more susceptible to heat stress due to the increased metabolic heat stress generated for rapid growth.

\section{Conclusion}

In these natural and technological conditions under the influence of summer heat stress, sows of the Poltava meat breed with a $12.5 \%$ share of the blood of the early maturing meat breed will be optimal for breeding, subject to correction of the conditions of keeping and feeding.

\section{References}

1. IPCC, 2018. Summary for Policymakers. In: Global Warming of $1.5^{\circ} \mathrm{C}$. An IPCC Special Report on the impacts of global warming of $1.5^{\circ} \mathrm{C}$ above pre-industrial levels 
and related global greenhouse gas emission pathways, in the context of strengthening the global response to the threat of climate change, sustainable development, and efforts to eradicate poverty, Masson-Delmotte, V., P. Zhai, H.-O. Pörtner, D. Roberts, J. Skea, P.R. Shukla, A. Pirani, W. Moufouma-Okia, C. Péan, R. Pidcock, S. Connors, J.B.R. Matthews, Y. Chen, X. Zhou, M.I. Gomis, E. Lonnoy, T. Maycock, M. Tignor, and T. Waterfield (eds.), World Meteorological Organization, Geneva, Switzerland, 32 pp, (2018).

2. O.S. Iyasereab, M. Batesonc, A.P. Bearda, J.H. Guy,J. of Thermal Biology, 99 (2021)

3. F. Wang, J. Zhang, International Journal of Environmental Research and Public Health, 16, 2202 (2019)

4. M.M. Rojas-Downing, A.P. Nejadhashemi, T. Harrigan, et al., Clim Risk Manag,16, 145-163(2017)

5. L.H. Baumgard, R.P. Rhoads, Annu. Rev. Anim. Biosci., 1, 311-337 (2013)

6. I.BelhadjSlimen,T.Najar,A.Ghram,M.Abdrrabba, J. Anim. Physiol. Anim. Nutr.,100, 401-412(2016)

7. V. Sejian, R. Bhatta, J.B. Gaughan, F.R. Dunshea, N. Lacetera, Animal,12, 431444(2018)

8. B. Xiaa,W. Wub, W. Fang, X. Wen, J. Xiea, H. Zhang, Heat stress-induced mucosal barrier dysfunction is potentially associated with gut microbiota dysbiosis in pigs,Animal Nutrition J. (2021)

9. R.P. Rhoads, L.H. Baumgard, J.K. Suagee, S.R. Sanders, Adv Nutr, 4, 267-276 (2013)

10. Ch. Wen, S. Wei, X.Zong, Y. Wang, M.Jin, Animal Nutrition J., 7(4), 1329-1336 (2021)

11. P. J. Hansen, J. W. Fuquayb, Heat Stress: Effects on Reproduction, Encyclopedia of Dairy Sciences (Third edition), 285-296 (2022)

12. S.Pham, J. S. Schultz, J. of Thermal Biology, 99,102954 (2021)

13. H. Guoab, Y. Yanga, Y. Qiao, J. Head, W. Yao, W. Zheng, Ecotoxicology and Environmental Safety, 227, 112916 (2021)

14. M.J.Carabaño,B.Logar,J.Bormann,J.Minet,M.-

L.Vanrobays,C.Díaz,B.Tychon,N.Gengler,H.Hammami, J. of Dairy Science,99, 37983814(2016)

15. G. Luna-Nevárez, A. L. Pendleton, R. I. Luna-Ramirez, S. W. Limesand, J. R. ReynaGranados, P. Luna-Nevárez, J. of Thermal Biology, 101, 103095 (2021)

16. A.M. Pereira, F.Jr. Baccari, E.A. Titto, J.A. Almeida, Int J Biometerol Jan. 52(3), 199208 (2008)

17. H.H. Le, M. Shakeri, H.A.R. Suleria, W. Zhao, R.M. McQuade, D.J. Phillips, EVidacs., J.B. Furness, F.R. Dunshea, V. Artuso-Ponte, etal. Antioxidants, 9, 1024 (2020) 